\title{
TURISMOS DE INTERIOR EN LA REGIÓN DE MURCIA. UNA APROXIMACIÓN AL TURISMO RURAL Y AL ENOTURISMO
}

\author{
Mercedes MILLÁN ESCRICHE \\ Escuela Universitaria de Turismo de Murcia
}

Recibido: 27/11/2011

Devuelto: 28/06/2012

Aceptado: 08/07/2012

RESUMEN: La evolución experimentada por el turismo que se ha desarrollado en el espacio interior de la Región de Murcia ha cobrado una identidad nueva a partir de la diversificación de su oferta. Actualmente, aun manteniendo el término interior por oposición al litoral, puede encontrarse una amplia gama de productos turísticos cuyo soporte territorial no es exclusivo del medio rural. Nos referimos al Turismo Cultural; Turismo Religioso; Turismo de Congresos, etc. Sin embargo también hay ofertas turísticas que mantienen un estrecho vínculo con lo rural, pues la materia prima en la que se fundamentan se obtiene a partir de las labores del campo. Un buen ejemplo es el Enoturismo que, desde la Certificación de las Rutas del Vino en Jumilla y Bullas, está siendo objeto de atracción turística en el espacio regional murciano.

Aquí pretendemos revisar el estado actual de dos productos turísticos que se sustentan territorialmente en el espacio interior rural de la Región de Murcia, por ello centran el interés de este trabajo el Turismo Rural y el Enoturismo.

PALABRAS CLAVE: Turismos de interior, Turismo Rural, Enoturismo, diversifcación turística.

INTERIOR TOURISM IN THE REGION OF MURCIA. AN APPROACH TO RURAL TOURISM AND WINE TOURISM

ABSTRACT: The evolution experienced by the tourism that has developed in the Interior of the region of Murcia has assumed a new identity from the diversification of its offer. Currently, you can find a wide range of tourist products whose territorial support are not exclusive to rural areas while remaining the internal term for opposition to the coast. We refer to the Cultural tourism; Religious tourism; Tourism of congresses, etc. However there are also tourist offers that keep a close link with the rural, as raw materials which are based is born of the Earth. A good example is the wine Tourism that, beginning with the certification of the routes of the wine in Jumilla and Bullas, is the subject of tourist attraction in the murcian regional space.

Here we intend to review the current state of two tourism products that are territorially based on the rural interior of the region of Murcia, therefore focused the interest of this work, the Rural tourism and wine Tourism.

KEY WORDS: Interior tourism, Rural tourism, Wine tourism, tourism diversification. 


\section{INTRODUCCIÓN}

La diversificación de la oferta turística en la Región de Murcia se manifiesta con mayor énfasis en los últimos años. La experiencia adquirida, junto a la identificación de los nuevos comportamientos de la demanda turística, han obligado a entender que el monocultivo turístico del sol y la playa no tienen razón de ser en un territorio con abundantes recursos diseminados por todo el espacio regional. Por un lado, porque la diversificación puede contribuir a un aprovechamiento más racional de esos recursos, a no exceder la capacidad de acogida y de carga de determinadas áreas; también porque la diversificación ayuda a desestacionalizar y a utilizar mejor las infraestructuras de comunicación y alojativas ${ }^{1}$ regionales. En definitiva, porque diversificar supone gestionar más y mejor lo que se tiene. No en vano la diversificación es una de las estrategias de reestructuración más intensamente utilizada por los responsables de los destinos turísticos maduros y uno de los retos que se imponen los destinos emergentes $y$, de igual modo, contribuye a mejorar las perspectivas de desarrollo en los espacios rurales (PLAZA, 2005)

De todo ello se deriva la amplia oferta del turismo regional, que se materializa en productos turísticos desarrollados fundamentalmente en el litoral, como el citado Sol y Playa o el Turismo Náutico, así como otros que se pueden encontrar en el interior o en ámbitos urbanos, ya sean éstos últimos del litoral o del interior. Nos referimos, como ejemplo, al Turismo Cultural Urbano o al Turismo de Reuniones en sus diferentes subtipologías: congresual, ferial, de incentivos y de negocios en general.

Por eso consideramos que hoy no tiene mucho sentido, en determinados territorios, referirse con exclusividad al turismo de interior. Desde el punto de vista conceptual resulta muy amplio y bajo una perspectiva geográfica reúne lo rural, lo urbano y lo natural. Por esa razón, en este contexto nos identificamos con VALENZUELA (1997) cuando se refiere no ya al turismo de interior, sino a los turismos de interior y su gran heterogeneidad.

En este artículo pretendemos exponer algunas consideraciones sobre las cuestiones anteriores y, en coherencia, referirnos a dos productos turísticos que se desarrollan principalmente en el interior de la Región de Murcia. Con

\footnotetext{
${ }^{1}$ Nos permitimos utilizar el término "alojativas" siguiendo a distintos autores e incluso a lo expresado en la normativa de distintas autonomías españolas. Sirva como ejemplo el Decreto número 75/2005, de 24 de junio, de la Región de Murcia, por el que se regulan los apartamentos turísticos y alojamientos vacacionales. Capítulo II SECCIÓN 2a De los requisitos mínimos de las unidades alojativas.
} 
ese objetivo, se ha optado por utilizar como método de análisis la revisión de normas y documentos oficiales procedentes de distintas administraciones. Así mismo, se ha consultado bibliografía de estudiosos sobre la materia, con aportaciones que enriquecen la experiencia propia adquirida en la elaboración de trabajos anteriores. A esto se ha unido la selección de aquellas fuentes estadísticas que nos permiten corroborar nuestros argumentos.

El trabajo se ha estructurado en tres apartados y unas conclusiones, todo ello acompañado de la correspondiente bibliografía. El primer apartado se titula turismo de interior o turismo en el espacio rural. A través de la normativa regional y otras fuentes, permite comprobar la ambigüedad existente a la hora de definir con precisión el concepto de Turismo de Interior y el de Turismo Rural. En el segundo y tercer apartados nos centramos, respetivamente, en la situación del producto Turismo Rural y el Enoturismo en la Región de Murcia, este último como producto turístico innovador que empieza a desarrollarse en el espacio rural regional.

\section{TURISMO DE INTERIOR O TURISMO EN EL ESPACIO RU- RAL}

No es la intención de esta aportación sentar preceptos a la hora de definir al Turismo de Interior, simplemente tratamos de justificar, a modo de reflexiones, el porqué de que en la actualidad dicho término acoja una oferta turística más diversificada que hace unos años, cuando casi era exclusiva su identificación con el Turismo Rural.

A nuestro juicio el término Turismo Rural es necesariamente más restrictivo porque, como se argumentará más adelante, exige el cumplimiento de premisas a todo juicio inexcusables. Sin embargo todavía es frecuente encontrar el calificativo genérico de "interior" cuando recurrimos a fuentes encargadas de facilitar datos sobre la oferta turística de la Región de Murcia. Un buen ejemplo es el que se constata en la clasificación que hace la Consejería de Cultura y Turismo y que presentamos en la TABLA 1. En ella se puede apreciar la neta diferencia entre litoral (Águilas, Cartagena, La Manga, Mar Menor y Mazarrón) e interior (del que se ha desagregado la capital de la Comunidad Autónoma).

Lo cierto es que, si se entiende desde una perspectiva estrictamente geográfica, el Turismo de Interior es todo aquel que se desarrolla fuera del espacio litoral ${ }^{2}$. En el caso de la Región de Murcia pareció entenderse así cuando

\footnotetext{
${ }^{2}$ Este espacio también debe entenderse aquí desde la perspectiva turística, más allá del Dominio Público Marítimo Terrestre y cuantos ámbitos se recogen legalmente para el litoral.
} 
se enunciaron las primeras definiciones de los alojamientos rurales murcianos. Para comprobarlo es imprescindible recurrir al cuerpo normativo del Turismo Rural que, antes de promulgarse la Ley 11/1997 de Turismo de la Región de Murcia, se sustentaba fundamentalmente en el Decreto 79/1992 de 10 de septiembre ${ }^{3}$. Dicho Decreto, en el Capítulo I, hace una descripción de la actividad, condiciones de los servicios y régimen del alojamiento. En su Artículo 1 expone: "Se crea la modalidad de alojamiento turístico especial en zonas del interior de la Región de Murcia".

Tabla 1: Distribución por zonas de la oferta turística de la Región de Murcia

\begin{tabular}{|c|c|c|c|c|c|c|}
\hline & $\begin{array}{c}\text { Estab. } \\
\text { hotel. }\end{array}$ & Apt. Tur. & $\begin{array}{l}\text { Cam- } \\
\text { pings }\end{array}$ & $\begin{array}{l}\text { Aloj. } \\
\text { Rur. }\end{array}$ & Rest. & Caf. \\
\hline Zonas & $N^{o}$ & $N^{o}$ & $N^{o}$ & $N^{o}$ & $N^{o}$ & $N^{o}$ \\
\hline Águilas & 15 & 87 & 2 & 1 & 53 & 8 \\
\hline Cartagena & 19 & 59 & 2 & 20 & 231 & 88 \\
\hline La Manga & 10 & 963 & - & - & 107 & 64 \\
\hline Mar Menor & 45 & 769 & 3 & 5 & 352 & 111 \\
\hline Mazarrón & 20 & 218 & 3 & 7 & 59 & 18 \\
\hline Interior & 29 & 322 & 8 & 477 & 577 & 81 \\
\hline Murcia & 39 & 58 & 1 & 10 & 551 & 102 \\
\hline \multirow[t]{2}{*}{ Total } & 227 & 2.385 & 19 & 520 & 1.930 & 480 \\
\hline & $\begin{array}{c}\text { Estab. } \\
\text { hotel. }\end{array}$ & Apt. Tur. & $\begin{array}{l}\text { Cam- } \\
\text { pings }\end{array}$ & $\begin{array}{l}\text { Aloj. } \\
\text { Rur. }\end{array}$ & Rest. & Caf. \\
\hline Zonas & Plazas & Plazas & Plazas & Plazas & & \\
\hline Águilas & 827 & 431 & 366 & 8 & & \\
\hline Cartagena & 1.711 & 200 & 1.621 & 117 & & \\
\hline La Manga & 4.463 & 4.478 & - & - & & \\
\hline Mar Menor & 4.413 & 3.011 & 7.726 & 36 & & \\
\hline Mazarrón & 899 & 1.097 & 2.524 & 20 & & \\
\hline Interior & 3.533 & 705 & 1.939 & 3.048 & & \\
\hline Murcia & 4.329 & 154 & 264 & 69 & & \\
\hline Total & 20.165 & 10.076 & 14.440 & 3.298 & & \\
\hline
\end{tabular}

FuENTE: Consejería de Cultura y Turismo. Datos a 31 de diciembre de 2010.

En el mismo Decreto la única exigencia que se imponía a una infraestructura de alojamiento para calificarla como rural era «que se encuentren ubicados fuera del litoral y de los cascos urbanos de los municipios costeros». A estos efectos se entendía por interior «al espacio de 5 kilómetros tierra adentro, medido desde el límite externo de la zona de dominio público marítimo terrestre». De nuevo, podemos referirnos a la TABLA 1 para comprobar

${ }^{3}$ Actualmente el Decreto vigente es el 76/2005 
que municipios como Águilas, Mazarrón, o Cartagena, entre otros, presentan oferta de alojamientos rurales, a pesar de reconocerlos en mayor medida por su condición de costeros y como destinos tradicionales de Sol y Playa.

Cabe señalar que el Decreto 79/1992 regulaba, de manera parcial, la actividad de alojamientos turísticos especiales en zonas de interior, encuadrándola entre las actividades turísticas reglamentadas, dentro de un concepto amplio de Turismo Interior. Decimos de forma parcial porque se limitaba a determinar las condiciones de esta modalidad de alojamientos, así como el procedimiento para su clasificación y a establecer que, en lo no previsto en dicho Decreto 79/1992, se aplicaría supletoriamente la normativa vigente en materia de alojamientos turísticos.

Con el marco legal que suponía el Decreto 79/1992, quedaban sin ningún tipo de regulación dos de los grupos que la Ley de Turismo de la Región de Murcia establece como Alojamientos Rurales: las hospederías rurales y las casas rurales en régimen compartido.

Es preciso recordar (MILLÁn, 2004), que la Ley de Turismo 11/1997, de 12 de diciembre ${ }^{4}$, será la que introduzca cambios sustanciales. En su Título II, artículo 22, determina que existe la tipología de Alojamientos Rurales, que son aquellos que cumplan los siguientes requisitos:

1.- Los que ofrezcan servicio de habitación o residencia, con o sin servicios complementarios, y que estén ubicados en un establecimiento que, reuniendo las instalaciones y servicios mínimos que reglamentariamente se determinen se sitúen fuera del litoral y de los cascos urbanos de los municipios costeros.

Las diferentes tipologías se integrarán en los siguientes grupos:

$\checkmark \quad$ Grupo A. Hospedería rural. Son establecimientos ubicados en edificaciones con valor arquitectónico tradicional, histórico o cultural, cedidos a los usuarios en régimen de alquiler por habitaciones.

${ }^{4}$ El Decreto 76/2005 de 24 de junio desarrolla y regula cada uno de los grupos de alojamientos rurales expresados por la Ley 11/1997. Presenta novedades respecto a las hospederías rurales, porque era necesario considerarlas con unas especiales particularidades y características; en cuanto a las casas rurales en alquiler, al completar la totalidad de características, requisitos tanto técnicos como administrativos y demás particularidades de este tipo de alojamientos, sin tener que recurrir, como hasta entonces a la aplicación de una normativa supletoria. Con relación a las casas rurales en régimen compartido porque eran una novedad de alojamiento respecto a los ya existentes en la Región de Murcia, y como tal era precisa su regulación. 
$\checkmark \quad$ Grupo B. Casas rurales de alquiler, en las que se cede el uso y disfrute de la vivienda en su totalidad.

$\checkmark \quad$ Grupo C. Casas rurales en régimen compartido, en las que el titular comparte el uso de la misma con una zona o anexo dedicada al hospedaje, en los términos anteriormente señalados.

2.- No tendrán la consideración de alojamientos rurales, cualquiera que sea su situación, los ubicados en pisos, considerando como tales las viviendas independientes en un edificio de varias plantas, salvo que se trate de una estructura unifamiliar.

Notamos, por lo tanto, que ya hay una explícita referencia a lo rural y con ello se puede diferenciar con mayor rigor si nos referimos a la oferta genérica de Turismo Interior, en la que tendrían cabida una diversidad de productos turísticos que están presentes fuera del espacio litoral de la Región de Murcia, o si estamos hablando de la más concreta de Turismo Rural.

Parece oportuno, en este contexto, remitirnos a organismos y normativas que realizan aportaciones sobre la consideración de lo rural. En el caso concreto de la OCDE, considera territorio rural a los municipios con una densidad inferior a los $150 \mathrm{hab} / \mathrm{km}^{2}$. Bajo ese criterio, hasta treinta municipios de la Región de Murcia pueden aceptarse como tales pero siempre entendiendo que, en muchos de ellos, lo verdaderamente rural se encuentra en sus entidades de población y no en las capitales municipales.

Por otro lado, el Real Decreto 752/2010, de 4 de junio, por el que se aprueba el primer programa de desarrollo rural sostenible para el período 2010-2014 (en aplicación de la $L E Y$ 45/2007, de 13 de diciembre, para el desarrollo sostenible del medio rural), también realiza una selección y clasificación de las zonas rurales de la Región de Murcia. En este contexto la zona rural es el ámbito de aplicación de las medidas derivadas del Programa de Desarrollo Rural Sostenible que establece los siguientes tipos:

a) Zonas rurales a revitalizar: aquellas con escasa densidad de población, elevada significación de la actividad agraria, bajos niveles de renta y un importante aislamiento geográfico o dificultades de vertebración territorial.

b) Zonas rurales intermedias: aquellas de baja o media densidad de población, con un empleo diversificado entre el sector primario, secundario y terciario, bajos o medios niveles de renta y distantes del área directa de influencia de los grandes núcleos urbanos. 
c) Zonas rurales periurbanas: aquellas de población creciente, con predominio del empleo en el sector terciario, niveles medios o altos de renta y situadas en el entorno de las áreas urbanas o áreas densamente pobladas.

Tabla 2: Zonas rurales de la Región de Murcia

\begin{tabular}{cccccc}
\hline Zona & Calif. & Prioridad & Población & $\begin{array}{c}\text { Sup } \\
\left(\mathrm{km}^{2}\right)\end{array}$ & $\begin{array}{c}\text { Mun., Ent. } \\
\text { Locales Menores }\end{array}$ \\
\hline Noroeste & $\mathrm{R}$ & $1^{\text {o }}$ & 61.421 & $2.297,77$ & $\begin{array}{c}\text { Calasparra, Caravaca de la } \\
\text { Cruz, Cehegín y Moratalla }\end{array}$ \\
\hline Valle de Ricote & $\mathrm{I}$ & $2^{\text {o }}$ & 15.111 & 336,80 & $\begin{array}{c}\text { Albudeite, Blanca, Campos } \\
\text { del Río, Ojós, Ricote, Ulea y } \\
\text { Villanueva del Río Segura }\end{array}$ \\
\hline Centro & $\mathrm{P}$ & & 68.828 & 980,24 & $\begin{array}{c}\text { Aledo, Alhama de Murcia, } \\
\text { Fuente Álamo de Murcia, } \\
\text { Librilla y Totana }\end{array}$ \\
\hline
\end{tabular}

$\mathrm{R}, \mathrm{A}$ revitalizar; I, Intermedia; $\mathrm{P}$, Periurbana

FuENTE: Real Decreto 752/2010, de 4 de junio

Lo que ocurre en esta Comunidad Autónoma no difiere demasiado de la situación que se vive en el ámbito geográfico nacional. Por ese motivo se tiende a aceptar que es el cumplimiento de determinadas premisas lo que finalmente define, al menos en lo que respecta a la infraestructura de acogida, al Turismo Rural. En este sentido, el INE considera que los alojamientos de Turismo Rural son: los establecimientos o viviendas destinadas al alojamiento turístico mediante precio, con o sin otros servicios complementarios y que estén inscritos en el correspondiente Registro de Alojamientos Turísticos de cada CCAA.

Dichos establecimientos se distinguen por:

$\checkmark$ Estar situados en un medio rural.

Ser edificaciones con una tipología arquitectónica propia de la zona o estar situados en fincas que mantienen activas explotaciones agropecuarias (agroturismo).

$\checkmark$ Ofrecer un número de plazas y habitaciones para el alojamiento de huéspedes limitado, además de reunir ciertos requisitos de infraestructura y dotaciones básicas.

De ello se deriva que la principal diferencia entre el genérico Turismo de Interior y el Turismo Rural se encuentra en las características de la base territorial en la que se sustenta y en la tipología de los alojamientos que deben 
cumplir con los condicionantes del medio en el que se inscriben: el espacio rural.

En trabajos anteriores (MILlÁN, 1998, 2000), concluíamos que la calificación de rural se obtiene tanto de la funcionalidad principal del territorio, la que reconocemos como seña de identidad del mismo, como de la ocupación primordial de sus habitantes. También podemos extraer argumentos de la definición de rural que hace el diccionario de la lengua española y que concreta como: perteneciente al campo y a las labores que en él se realizan.

Actualmente contamos con otros argumentos de peso por sustentarse en una base legal, aunque, a nuestro juicio, demasiado condicionados por cuántos son, más que por quiénes son y a qué se dedican. Así, y a los efectos de la antes citada LEY 45/2007, de 13 de diciembre para el desarrollo sostenible del medio rural, se entiende por:

a) Medio rural: el espacio geográfico formado por la agregación de municipios o entidades locales menores definido por las administraciones competentes que posean una población inferior a 30.000 habitantes y una densidad inferior a los 100 habitantes por $\mathrm{km}^{2}$.

b) Zona rural: ámbito de aplicación de las medidas derivadas del Programa de Desarrollo Rural Sostenible regulado por esta Ley, de amplitud comarcal o subprovincial, delimitado y calificado por la Comunidad Autónoma competente.

c) Municipio rural de pequeño tamaño: el que posea una población residente inferior a los 5.000 habitantes y esté integrado en el medio rural.

Lo más interesante de esta Ley, en el contexto que nos ocupa, es que en el Capítulo VI: Medidas para el desarrollo rural sostenible, en su Artículo 20. Diversificación Económica, considera necesario fomentar el Turismo Rural, en particular a través de una adecuada ordenación de la oferta y la mejora de la demanda turística. Señala que debe realizarse una atención preferente al fomento de un turismo sostenible en las zonas rurales prioritarias y al Agroturismo o turismo ligado a la actividad agraria. De todo ello podemos extraer que se pretende llegar a la consideración de un medio rural multifuncional, sin la exclusividad de lo agrario y con la concurrencia de actividades y actores diversificados.

\section{CARACTERIZACIÓN DEL TURISMO RURAL EN LA REGIÓN DE MURCIA}

Alcanzar una definición consensuada sobre Turismo Rural sigue siendo algo complejo, tanto en esta Comunidad Autónoma como en otras del Estado 
español. Sin embargo, aun reconociendo las mutaciones advertidas en los espacios rurales en las últimas décadas, para el desarrollo de esta modalidad turística es preciso mantener las actividades tradicionales de dicho medio por parte de las poblaciones receptoras.

La necesidad de experimentar las particularidades de un mundo rural vivo, subyace en buena parte de las motivaciones de la demanda del producto turístico mencionado. Emular la cotidianeidad de los pueblos, hacer esfuerzos por imponer un falso tipismo, no sirve para estimular y decidir a visitar un destino rural a quien está dispuesto a pagar por "consumir" experiencias enriquecedoras basadas en la autenticidad.

Sabemos que las iniciativas propugnadas desde instancias europeas apoyan la multifuncionalidad de los espacios rurales. En este sentido, algo que se asocia al Turismo Rural de la Región de Murcia es su estrecha vinculación con las políticas de desarrollo rural emanadas de las diferentes administraciones, porque desde sus inicios este producto turístico ha estado vinculado a iniciativas que lo han impulsado. Nos referimos a políticas comunitarias que, desde hace tiempo, han entendido la incorporación de la función turística en el medio rural como un revulsivo para la dinamización de sus economías y que hoy vemos reflejado en la ya citada LEY 45/2007. Así mismo, además de la propia actividad empresarial, podemos descubrir en el Programa de Desarrollo Rural de la Región de Murcia 2007-2013 la importancia de estas ayudas ${ }^{5}$.

No podemos entrar a mencionar todas las medidas que aparecen en el Programa, pero parece oportuno destacar la medida 413, destinada a financiar los objetivos del Eje 3 del PDR (Medidas 311, 312, 313, 321, 323 y 331 del enfoque Leader). Con un gasto público total programado para el período 2007-2013 de 24.039.267 euros, corresponden a la financiación del FEADER 18.029.450 euros y, a nuestro juicio, las medidas establecidas pueden suponer un buen impulsor para avivar el desarrollo turístico de los espacios rurales de la Región de Murcia. Nótese que la medida 313 está exclusivamente destinada al Fomento de actividades turísticas y tiene una dotación de 5.402.234 euros.

Por Orden de 26 de marzo de 2009 se seleccionaron los 4 Grupos de Acción Local (GAL) presentados para concretar las acciones en sus diferentes

\footnotetext{
${ }^{5}$ Medidas Eje 3: diversificación hacia actividades no agrícolas; ayudas a la creación y al desarrollo de microempresas; fomento de actividades turísticas; prestación de servicios básicos para la economía y la población rural; conservación y mejora del patrimonio; formación e información.
} 
ámbitos territoriales. La firma de los correspondientes convenios se realizó el 23 de febrero de 2010. Los 4 GAL son:

1) Asociación para el Desarrollo Rural CAMPODER;

2) Integral, Sociedad para el Desarrollo Rural;

3) Asociación para el Desarrollo Comarcal del Nordeste de la Región de Murcia;

4) Asociación para el Desarrollo Rural Integrado de los municipios de la Vega del Segura.

Figura 1. Medidas PDR de la Región de Murcia y distribución del gasto

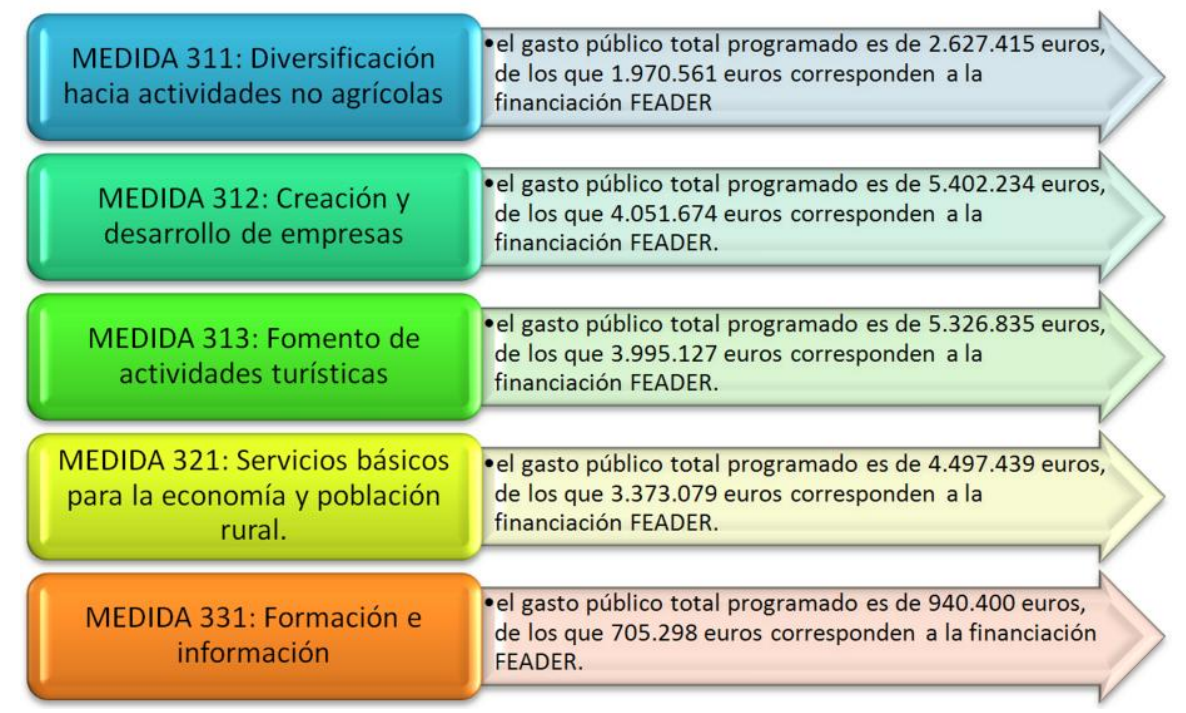

FuENTE: elaboración propia con datos del Programa de Desarrollo Rural de la Región de Murcia 2007-2013.

\section{III.1. Oferta del Turismo Rural en la Región de Murcia.}

Efectivamente, la primera etapa del Turismo Rural regional estuvo estrechamente vinculada a las acciones emprendidas desde la Iniciativa Comunitaria LEADER, como desarrollamos ampliamente en MILLÁN (2004). Con sus luces y sombras contribuyó a estimular la rehabilitación del patrimonio rural y disponerlo como infraestructura turística; a reavivar pequeñas industrias artesanas y a crear un ambiente más favorable hacia el acogimiento de turistas. Lo cierto es que, aun hoy, se siguen considerando muy positivas las estrategias que favorecen la dinamización rural a través del turismo. 
Gráfico 1. Alojamientos rurales en la Región de Murcia (1994-2001)

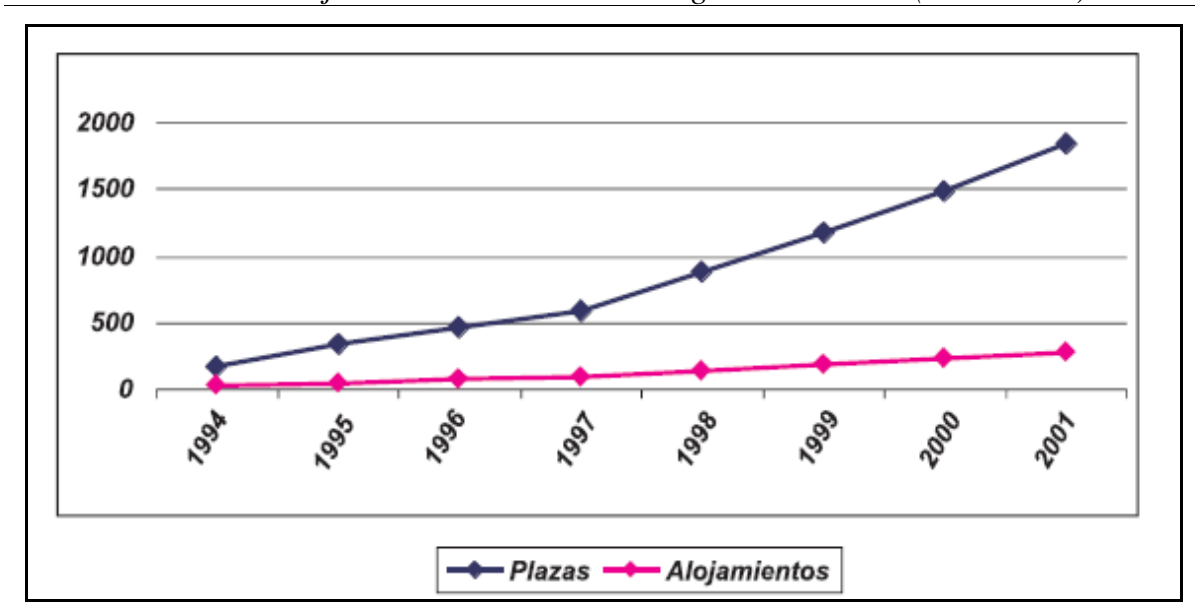

FuENTE: Millán (2004).

Gráfico 2. Evolución de la oferta de Casas Rurales en la Región de Murcia: Establecimientos y Plazas (2002-2010)

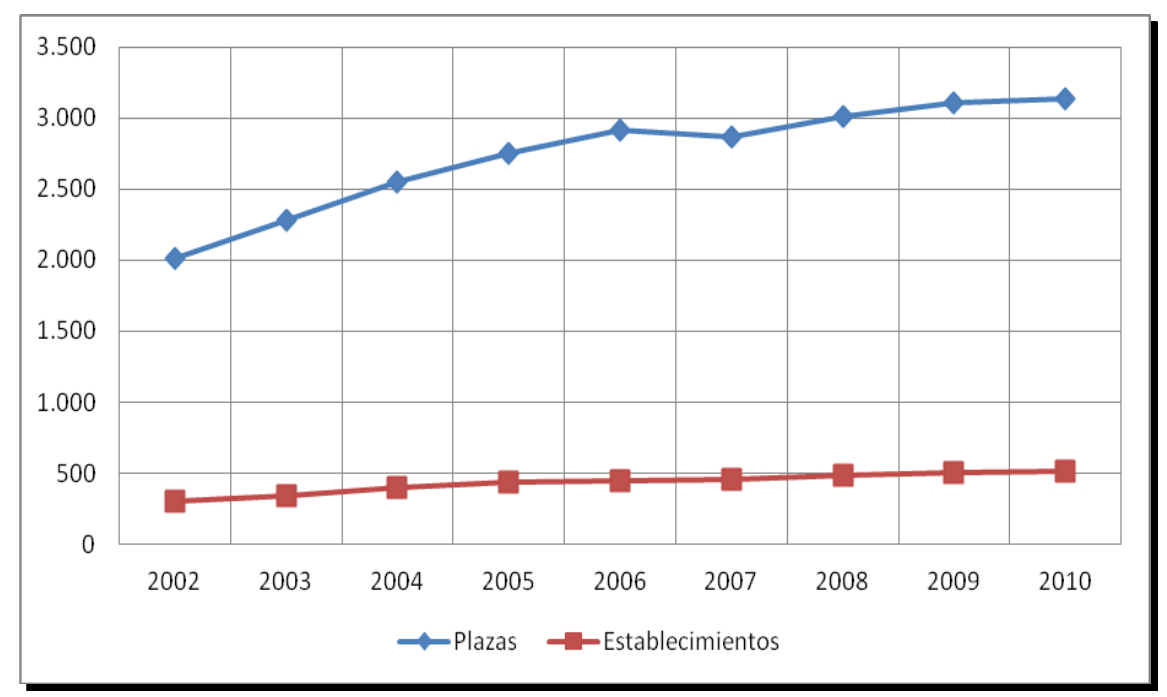

FuENTE: Elaboración propia a partir de datos de la Consejería de Cultura y Turismo. Dirección General de Infraestructuras de Turismo CARM.

En esos antecedentes, (GRÁFICOS 1 y 2), podemos encontrar el germen de lo que ocurre en la actualidad. El producto Turismo Rural se encuentra diseminado por todo el territorio de la Comunidad (GRÁFICO 3) y ahora son muy pocos los municipios que no cuentan con algún alojamiento que favo- 
rezca la oferta de esta tipología turística. No obstante, hay que insistir en el mantenimiento de la mayor concentración de oferta en los municipios pioneros, sobre todo en el noroeste y más aún Moratalla, municipio que sigue destacando de forma muy evidente sobre los demás. Se acompaña el mapa de la Región para una mejor localización de los municipios (FIGURA 2).

Gráfico 3. Casas rurales por municipios. Región de Murcia (evolución 20072010)

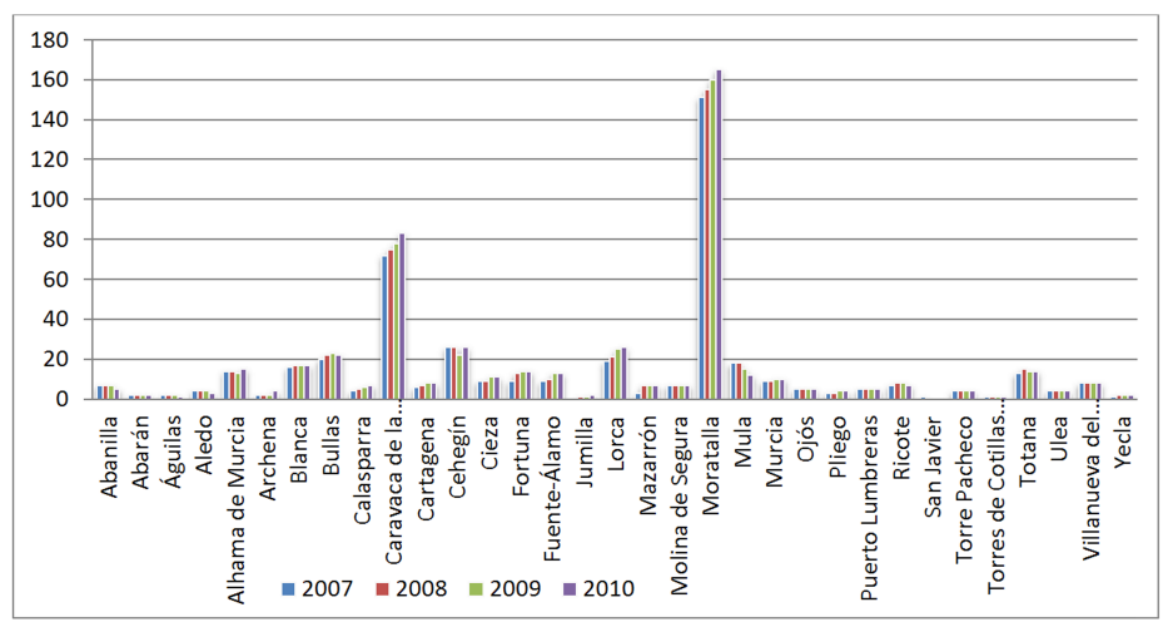

FUENTE: Elaboración propia a partir de datos del Centro Regional de Estadística de Murcia

\section{III.2. Caracterización de la demanda del Turismo Rural en la Región de Murcia.}

Además de acreditar que ha existido un desarrollo significativo de la oferta de Turismo Rural en este territorio, consideramos apropiado comprobar el perfil de la demanda de este producto turístico que llega a la Región. Las características más destacadas, que se extraen de los estudios sobre el comportamiento de la demanda que viene realizando la Unidad de Estudios y Estadística de la Consejería de Cultura y Turismo de esta Comunidad, son las que se exponen a continuación de forma sintetizada:

El origen es mayoritariamente nacional, incluso un alto porcentaje es de la propia Región. La Comunidad Valenciana aporta el 41.2\%; le sigue Madrid con el 17,6\%; un 11,8\% procede de Cataluña y se repite el mismo porcentaje para los turistas que llegan de Andalucía. El 17.6\% restante se distribuye entre diferentes procedencias menos significativas. 
Figura 2. La Región de Murcia

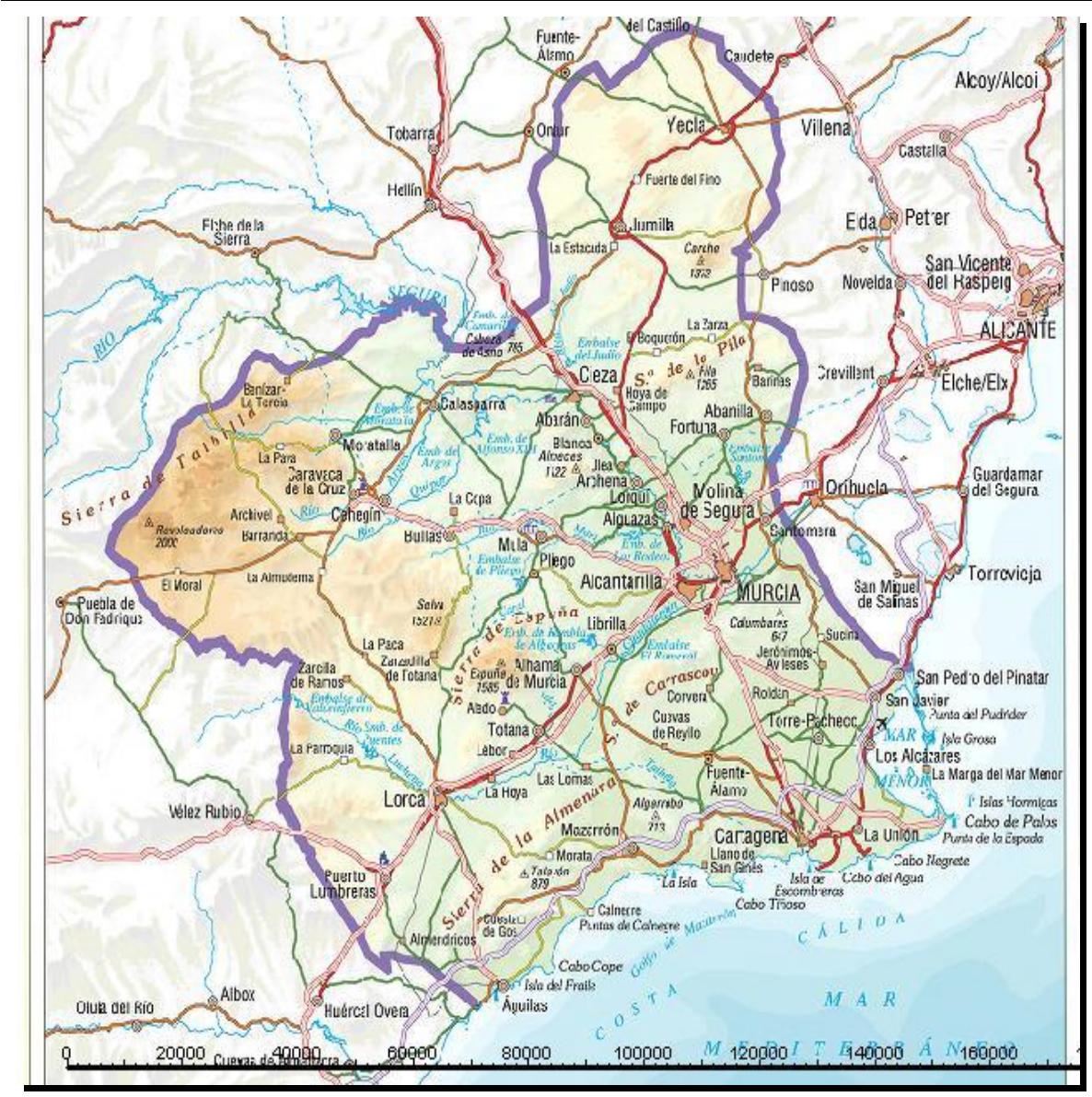

FUENTE: http://cartomur.imida.es/

La oferta de Turismo Rural de la Región de Murcia viene siendo conocida por dos vías fundamentales: la información transmitida por amigos o familiares (el tradicional "boca a boca" o "boca a oreja"), con el 49,2\% y la obtenida por los propios turistas en visitas anteriores a esta Comunidad Autónoma, con el $41 \%$ del total. Ante estos porcentajes resultan bastante insignificantes el 6,6\% que representa la información obtenida a través de Internet y el $4,9 \%$ que es transmitida en las oficinas de turismo. Existe un 6,6\% restante que han utilizado otras vías de información de las que no se tienen los detalles. 
Los turistas son preferentemente jóvenes, siendo el rango de edad más importante el de 26 a 35 años, con un 46,8\%. Les siguen los de 36 a 45 años con el $19,4 \%$.

Suelen viajar en familia un $(37,1 \%)$ y en pareja $(30,6 \%)$ y se desplazan principalmente en vehículo propio (un 79\%).

$\checkmark$ La duración de la estancia es de hasta tres días para un 35,5\%, seguido de la estancia de entre 4 y 7 días, con un $29 \%$. La estancia media se realiza entre 3 y 4 días.

$\checkmark$ El tipo de alojamiento más utilizado es la vivienda, con casi un $50 \%$ de turistas, seguido de la casa rural con un $27,4 \%$.

$\checkmark$ Con respecto a su comportamiento en el medio rural, hay que destacar que el turista rural no solo disfruta de actividades en el medio rural y de naturaleza (el 79,5\%), sino que también tienden a realizar actividades fuera del medio rural como la visita a monumentos y museos $(15,4 \%)$ y entretenimiento nocturno con un $35,9 \%$.

Un punto poco positivo es el referente al gasto medio de la demanda de este producto turístico en la Región de Murcia. El turista rural gasta menos que el turista cultural o de sol y playa y sobre todo que el turista de golf o de congresos. El gasto medio de los turistas rurales es de 48,34 euros al día, señalando que el gasto del turista nacional es mayor que el del extranjero. Este gasto va dedicado principalmente al alojamiento, restaurantes, comestibles y bebidas.

Una cuestión importante es la fidelización del cliente y, en este sentido, los turistas que eligen la Región como destino turístico rural repiten en un $67,3 \%$. Esto se debe a que la satisfacción general es de 7,6 puntos, destacando el confort y la relación calidad-precio del alojamiento rural. De esta manera, se produce una importante promoción del destino, ya que se recomienda a familiares y amigos.

Hay que añadir que también se procura captar turistas mediante otros medios propios del marketing. En este sentido, las estrategias para atraer a la demanda de Turismo Rural, basadas en publicidad, que más éxito tienen son las realizadas a través de Internet, ya que el 45,5\% de los encuestados lo señalan como tal. Le sigue televisión con el $42,4 \%$ y cabe destacar el escaso rendimiento obtenido con la presencia en ferias porque solo representa el $9,1 \%$ del total. 
TABLA 3: Infraestructura de alojamiento utilizado (\%)

\begin{tabular}{|c|c|c|c|c|c|}
\hline & Hotel & Camping & C. Rural & Vivienda & Otro \\
\hline \multicolumn{6}{|c|}{ Lugar de procedencia } \\
\hline Región de Murcia & - & 15,4 & 23,1 & 61,5 & \\
\hline España (exc. Murcia) & 14,7 & 11,9 & 35,3 & 35,3 & 2,9 \\
\hline Extranjero & - & 20,0 & 13,3 & 66,7 & \\
\hline \multicolumn{6}{|c|}{ Con quien viaja } \\
\hline Solo & - & - & - & 100,0 & - \\
\hline Con familia & 13 & 17,4 & 26,1 & 43,5 & \\
\hline Con amigos & 11.1 & 22,2 & 55,6 & - & 11,1 \\
\hline En pareja & 5,3 & 15,8 & 31,6 & 47,4 & \\
\hline \multicolumn{6}{|c|}{ Zona de alojamiento } \\
\hline Noroeste & 12,0 & 12,0 & 12,0 & 64,0 & \\
\hline Valle de Ricote & - & - & 84,6 & 15,4 & - \\
\hline Sierra Espuña & 9,5 & 28,6 & 9,5 & 47,6 & 4,8 \\
\hline Resto & - & - & 33.3 & 66,7 & \\
\hline \multicolumn{6}{|c|}{ Comunidad Autónoma } \\
\hline Andalucía & 50,0 & - & 25,0 & 25,0 & - \\
\hline Cataluña & & - & 75,0 & 25,0 & \\
\hline Comunidad Valenciana & 21,4 & 7,1 & 28,6 & 35,7 & 7,1 \\
\hline Madrid & - & - & 33,3 & 66,7 & \\
\hline \multicolumn{6}{|c|}{ País } \\
\hline Reino Unido & - & 33,3 & 33,3 & 33,3 & \\
\hline Francia & - & 50,0 & - & 50,0 & \\
\hline Total & 8,1 & 15,5 & 27,4 & 48,4 & 1,6 \\
\hline
\end{tabular}

FUENTE: CARM Estudio sobre el comportamiento de la demanda de Turismo Rural (verano 2008)

Es preciso matizar que la similitud de los resultados alcanzados durante varios años, nos ha llevado a poner como referencia los de 2008 (último de esta serie de estudios) ${ }^{6}$. En 2010 el análisis, de la Unidad de Estudios y Estadística de la Consejería de Cultura y Turismo, se limitó al Turismo Rural que se desarrolla en la Comarca del Noroeste de la Región de Murcia. Por ese motivo no podemos incluir datos más actualizados ni realizar un estudio comparativo con los datos de $2008^{7}$.

\footnotetext{
${ }^{6}$ Estudio sobre el comportamiento de la demanda de Turismo Rural (2008) CARM. Consejería de Cultura y Turismo. Secretaría General, Unidad de Estudios y Estadística.

7 http://www.carm.es/web/pagina?IDCONTENIDO=24563\&IDTIPO=100\&RASTRO= $\underline{\mathrm{c} 619 \$ \mathrm{~m} 11330,27341}$
} 
Gráfico 4. Profesión y situación laboral de la demanda de Turismo Rural (2008)

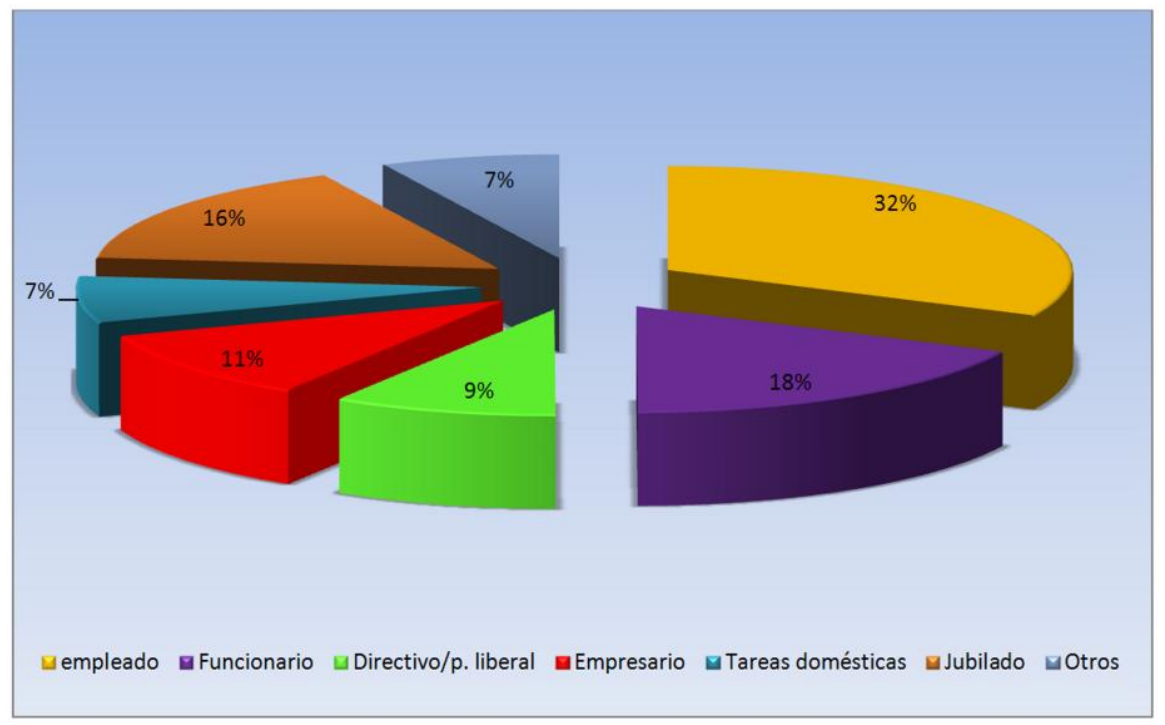

FUENTE: CARM Estudio sobre el comportamiento de la demanda de Turismo Rural (verano 2008)

Tabla 4: Encuesta de ocupación de los alojamientos rurales Región de Murcia

\begin{tabular}{lrrrrrr}
\hline & \multicolumn{3}{c}{ Número de viajeros } & \multicolumn{5}{c}{ Número de pernoctaciones } \\
\cline { 2 - 7 } & Total & Res. Esp. & Res. Extr. & Total & Res. Esp. & Res. Extr. \\
\hline \multicolumn{7}{c}{ Murcia } \\
\hline 2010 & 32.277 & 31.053 & 1.225 & 85.337 & 82.112 & 3.224 \\
2009 & 31.748 & 30.981 & 769 & 102.642 & 96.567 & 6.076 \\
(Var.) & 1,7 & 0,2 & 59,3 & $-16,9$ & -15 & $-46,9$ \\
\hline \multicolumn{7}{c}{ España } \\
\hline 2010 & 2.666 .449 & 2.378 .140 & 288.309 & 7.674 .431 & 6.387 .551 & 1.286 .880 \\
2009 & 2.708 .584 & 2.441 .521 & 267.062 & 7.901 .745 & 6.637 .824 & 1.263 .921 \\
(Var.) & $-1,6$ & $-2,6$ & 8 & $-2,9$ & $-3,8$ & 1,8 \\
\hline (Var.), Variación año anterior $(\%)$ & & & &
\end{tabular}

FUENTE: Encuesta de Ocupación de alojamientos de Turismo Rural. INE

La conclusión a la que puede llegarse, con los datos presentados, es que a pesar de la evolución tan positiva que hemos observado, en lo relativo a la expansión de la oferta de alojamientos y plazas de Turismo Rural en la Región de Murcia, la TABLA 4 pone de relieve que en los últimos años han experimentado un incremento los viajeros que han llegado a los alojamientos rurales, sobre todo los residentes en el extranjero, pero con un descenso bastante significativo de las pernoctaciones entre 2009 y 2010. Además, el porcentaje de dicho descenso es notablemente superior (14\% más) al del con- 
junto de España que pierde un 2,9\%. Por otro lado hay que contemplar que este comportamiento se intensifica cuando se trata de la demanda procedente del extranjero, ya que en ese caso se dispara la diferencia, porque mientras el conjunto nacional obtiene un $1,8 \%$ de incremento, la Región de Murcia pierde un $46,9 \%$.

Si se mantiene esta tendencia será obligatorio reformular la planificación de esta oferta turística y contemplar los fallos que presentan determinados alojamientos rurales e incluso algunos destinos de Turismo Rural. Ciertas estrategias pueden focalizarse en la creación, por parte del empresariado turístico, de actividades complementarias lo suficientemente atractivas como para motivar a la demanda a permanecer más tiempo en el lugar de acogida.

No hay que olvidar que reducir la consideración de un producto turístico a la exclusiva oferta de alojamiento en el espacio rural, es un error que deriva en la pérdida de competitividad del propio destino turístico, por ello es tan importante considerar la necesidad de realizar una planificación integrada del mismo. Entre otras cuestiones, como el estudio de la motivación de la demanda para elegir un producto turístico y un destino entre otros muchos, conviene atender al concepto de satisfacción del turista. RYAN $(1995,1997)$ considera que la satisfacción se origina con la calidad de la experiencia respecto a las expectativas creadas. El turista percibe su satisfacción como un éxito al conseguir lo que creía importante de antemano, algo que deben tener en cuenta los gestores del Turismo Rural de la Región de Murcia.

\section{ENOTURISMO EN LA REGIÓN DE MURCIA}

A priori el Enoturismo puede constituirse en producto turístico por sí mismo y en España, como en otros países, hay magníficos ejemplos de ello. Sin embargo, su representatividad en determinados territorios se ciñe a significar una de las múltiples posibilidades de complementar al Turismo Rural u otras ofertas turísticas. Por otro lado, la complejidad que existe a la hora de diferenciar si la infraestructura de alojamiento nace por y para este producto turístico, impide determinarla y analizarla con demasiada precisión.

Según VINTUR, el Enoturismo se sustenta en "la existencia previa de una cultura del vino (o viticultura), que junto al espacio geográfico en el que se desarrolla y las infraestructuras necesarias para ponerlo en disposición de consumo, constituyen los recursos básicos para su transformación en producto turístico". Desde esta perspectiva, no podemos exigir que la tipología de las infraestructuras de acogida de los enoturistas cumpla unos determinados cánones y es frecuente encontrar todo un abanico de posibilidades. 
En el caso concreto de la oferta enoturística de la Región de Murcia, es preciso advertir que es una oferta relativamente reciente y escasamente desarrollada y que sus consumidores no siempre se pueden considerar turistas. Como se sabe existen ya bastantes debates acerca del mantenimiento de la pernoctación como esencia fundamental de lo que es, o no, turismo. Pues bien, la modalidad de consumición del Enoturismo más extendida, en la Región de Murcia, apenas podemos integrarla en el turismo propiamente dicho ${ }^{8}$ porque responde, fundamentalmente, a la condición de excursionismo. Sin embargo, su existencia como producto turístico viene avalada por el reconocimiento de dos Rutas del Vino Certificadas como tales por la Secretaría de Estado de Turismo: la Ruta del Vino de Jumilla y la Ruta del Vino de Bullas.

Figura 3. Logotipos de las Rutas del Vino de Jumilla y Bullas
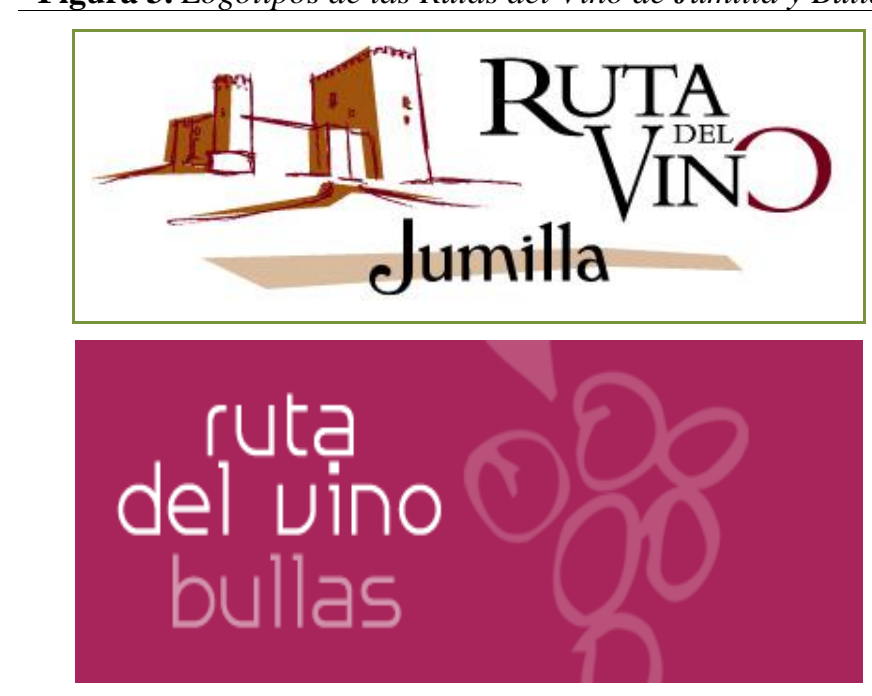

FUENTE: http://www.rutadelvinojumilla.com/v2/esp/, http://www. rutadelvino.bullas.es/index.htm

En este sentido conviene recordar que una Ruta del Vino Certificada supone para la entidad de certificación, "la integración bajo un mismo concepto temático de los recursos y los servicios turísticos de interés, existentes y potenciales, de una zona vitivinícola. Todo ello planteado desde la autenticidad y la vocación vivencial y con el fin de construir un producto desde la identidad propia del destino; facilitar la comercialización conjunta de toda

\footnotetext{
${ }^{8}$ Según la OMT
} 
la zona y garantizar el nivel de satisfacción de la demanda, impulsando así el desarrollo económico-social integral de la misma".

Para la Secretaría de Estado de Turismo, una Ruta del Vino Certificada deberá estar integrada, como mínimo, por los siguientes recursos:

$\checkmark \quad 15 \%$ de las bodegas de la zona que cumplan la totalidad de los requisitos de acreditación.

$\checkmark \quad$ Un volumen de oferta representativa: mínimo 5 establecimientos de restauración, 3 establecimientos de alojamiento, 2 comercios de productos enológicos.

$\checkmark \quad$ La Administración Turística y las Asociaciones Empresariales de Hostelería y Restauración deberán tener, preferiblemente, representación en el Ente Gestor.

Lo que nadie duda es que en ambos municipios existe una cultura previa del vino y que sus infraestructuras de acogida cumplen los requisitos establecidos por la Secretaría de Estado de Turismo. Por ello, desde esa perspectiva podemos decir que hay oferta de Enoturismo en la Región de Murcia.

Foto 1. Museo del Vino de Jumilla

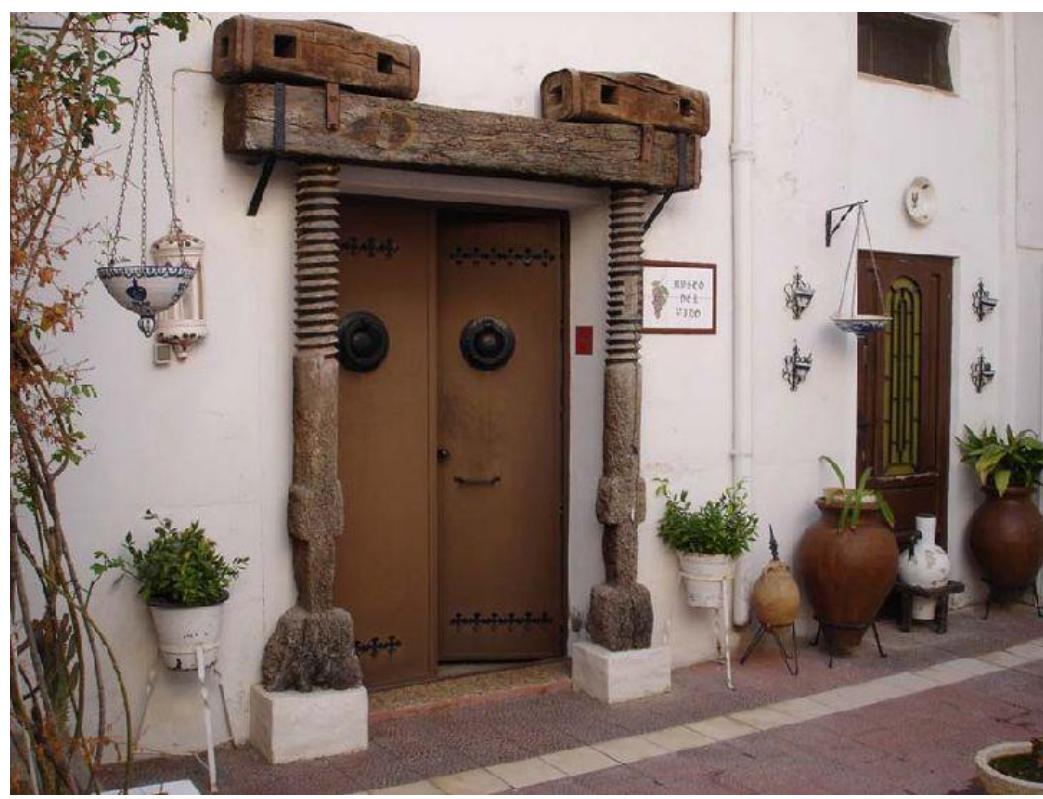

FuENTE: Región de Murcia Digital. 
La Ruta del Vino de Jumilla, cuya Denominación de Origen es la más antigua de la Región (1961), se certificó en 2005 y la de Bullas en 2007. Desde esas fechas están realizando notables esfuerzos para convertirse en destinos enoturísticos atractivos para la demanda. Así lo avala su adhesión a los objetivos de la Carta Europea del Enoturismo y la participación en proyectos cuyo objetivo es introducir el concepto de responsabilidad social territorial aplicado a las Rutas del Vino o territorios enoturísticos participantes.

Entre los objetivos de estos territorios cabe resaltar los siguientes:

$\checkmark \quad$ Diferenciarse como territorio, especialmente en materia de turismo.

$\checkmark \quad$ Trazar, en materia de turismo, objetivos más ambiciosos. turismo.

Implicar en su política, en mayor medida, a todos los agentes del

$\checkmark \quad$ Influenciar el desarrollo del turismo en su territorio.

$\checkmark \quad$ Fortalecer las actividades de sensibilización de los visitantes.

$\checkmark \quad$ Favorecer en el territorio un desarrollo socioeconómico que respete el medioambiente.

$\checkmark \quad$ Desarrollar productos turísticos originales, de calidad y altamente competitivos, tanto en los mercados nacionales como internacionales.

$\checkmark \quad$ Dotarse de un conjunto de instrumentos para evaluar las políticas turísticas.

Las actuaciones emprendidas por ambos municipios son abundantes. Así, podemos destacar la musealización de todo el proceso de producción y elaboración vinícola en el caso de Bullas y su participación como anfitriones en la IV edición del Congreso Museos del Vino de España, organizada desde la Asociación de Museos del Vino de España.

En el caso de Jumilla se puede citar el desarrollo de acciones formativas para los integrantes de la Ruta del Vino de Jumilla. Éstos se enmarcan dentro del Proyecto Piloto denominado 'Hacia un modelo de competitividad, sostenibilidad y gobernanza en el Medio Rural: Territorio enoturístico socialmente responsable', suscrito por el MARM y Acevin para el periodo 2009-2011 y financiado por el Ministerio de Medio Ambiente, Medio Rural y Marino y las Rutas. 
Desde el punto de vista de las infraestructuras turísticas, Jumilla presenta una oferta de alojamiento integrada por tres hoteles (dos de tres estrellas y uno de dos) y dos pensiones, que le permiten disponer de un total de doscientas once plazas. Por su parte Bullas, además de alojamientos rurales y el Camping La Rafa, tiene dos hoteles y dos pensiones que aportan sesenta y cinco plazas al conjunto de la oferta municipal.

Foto 2. Museo del Vino de Bullas (interior)

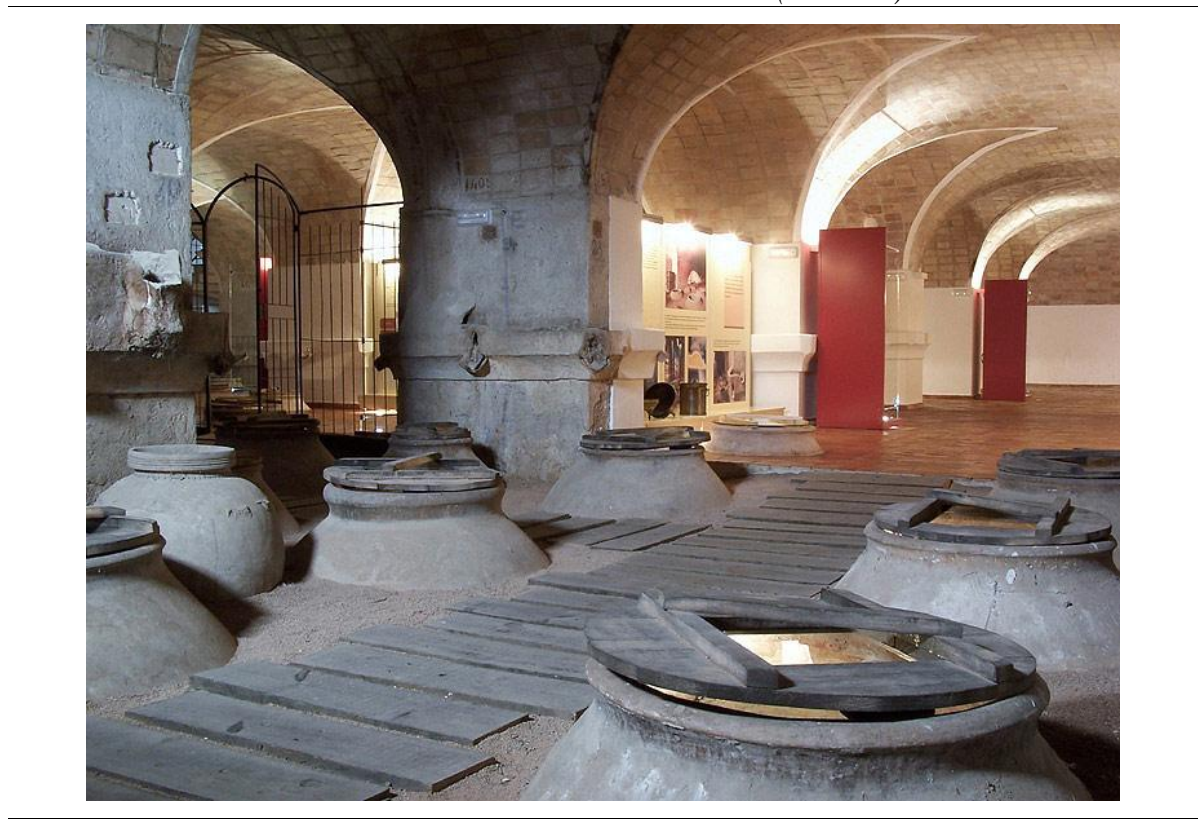

FUENTE: http://www.museodelvino.bullas.es/eng/exposicion/

La importancia de la hotelería, como modalidad de alojamiento para la actividad enoturística, se ha puesto de relieve en otros territorios. En ellos se ha apostado por ofrecer la posibilidad de alojarse en hoteles de altas categorías (Hotel Marqués de Riscal Luxury Collection, en La Rioja, o el Hotel Arzuaga Navarro de Quintanilla de Onésimo, entre otros muchos). Con ello se amplían los segmentos de la demanda que se sienten atraídos por el Enoturismo y que, sin embargo, no se identifican con realizar sus alojamientos en casas rurales u otras tipologías del medio rural.

Es preciso recordar que los enoturistas se diferencian por:

$\checkmark$ Disfrutar el vino. 
Ampliar u obtener conocimientos sobre la cultura del vino, en contextos geográficos diferentes y con variedades en las producciones.

Experimentar y conocer el proceso de elaboración del vino in situ, desde la tierra hasta su comercialización.

Todo ello sin renunciar a conocer y disfrutar el medio rural: su población, la cultura rural, sus actividades, eventos y tradiciones.

Para Jumilla y Bullas, según la información recabada en sus Oficinas de Turismo (no se elaboran estadísticas oficiales de este producto turístico), la certificación de sus respectivas rutas ha contribuido al aumento de visitantes. Sin embargo no ha sido posible conseguir datos desagregados acerca de la demanda estrictamente enoturística, es decir, separada de la genérica de Turismo Rural. Esta carencia, que afecta a los dos municipios, se convierte en un reto que abre vías de investigación para los interesados en esta tipología turística.

Con los datos facilitados solo podemos señalar que en el Altiplano murciano, integrado por los municipios de Jumilla y Yecla (otro municipio que cuenta con vinos con Denominación de Origen), se han registrado, en 2010, 16.779 viajeros que realizaron 25.629 pernoctaciones. En 2011 fueron 14.821 los turistas que llegaron a dicho Altiplano regional y realizaron 24.414 pernoctaciones. Esta escueta información se restringe aun más para el caso de Bullas, donde la falta de información propia para el municipio nos obligaba a presentar resultados que son compartidos por el mismo Bullas, Caravaca, Cehegín y Moratalla, por lo que, a nuestro juicio, carecen de interés para este estudio.

\section{CONCLUSIONES}

En la Región de Murcia, puede reconocerse el Turismo de Interior por su oposición, desde una perspectiva geográfica, al que se desarrolla en el espacio costero. Sin embargo, en este trabajo se ha optado por la consideración más amplia de Turismos de Interior, con una gama de ofertas diversificada que representan a diferentes destinos turísticos de la propia Región de Murcia.

De forma más precisa, por cuestiones obvias de extensión, se han analizado productos turísticos que se desarrollan en el interior de esta Comunidad y en espacios que pueden identificarse claramente con una funcionalidad rural. Se trata del Turismo Rural y el Enoturismo.

Respecto al Turismo Rural, la oferta se extiende por buena parte de los municipios de la Región, aunque siguen siendo más representativos los que 
se localizan en el noroeste. Dicho ámbito geográfico fue pionero en esta materia y por sus particularidades se hizo merecedor de las acciones emanadas de iniciativas de la Unión Europea, sobre todo de la Iniciativa LEADER. No cabe duda que este producto turístico ha experimentado una evolución muy positiva en términos de oferta y respuesta de la demanda. Sin embargo, es preciso llamar la atención sobre los resultados de los últimos años porque muestran un descenso de las pernoctaciones y, como consecuencia, se aconseja emprender un reposicionamiento competitivo del producto renovando sus estrategias de gestión y mejorando la calidad de la oferta normalizada, a la vez que se controla de forma más exhaustiva la oferta que permanece al margen de la legalidad.

Por lo que se refiere al Enoturismo, entendemos que la fase de desarrollo en la que se encuentra en el territorio murciano, que podemos considerar emergente, permite establecer acciones que favorezcan su crecimiento bajo estrictos criterios de calidad. Este producto turístico, que aúna herencia e innovación en todo lo referente a la cultura del vino que lo sustenta, cuenta con vinos de excelente calidad reconocidos en ámbitos internacionales y en consonancia precisa de instalaciones e infraestructuras capaces de atraer mercados con poder adquisitivo alto. Los gestores del Enoturismo en la Región de Murcia tienen que ser conscientes de que si la demanda enoturística sólo encuentra espacios con buenos vinos, pero sin una infraestructura de alojamientos de calidad y sin actividades complementarias que justifiquen su desplazamiento, el desarrollo del producto en Jumilla y Bullas, así como el incipiente de Yecla, se mantendrá como mera oferta para realizar excursiones.

Al mismo tiempo, conviene recordar que para establecer las estrategias antes mencionadas, es preciso avanzar en el conocimiento de la auténtica oferta y demanda de Enoturismo y para ello se necesitan aportaciones y estadísticas que desagreguen la información por municipios y por productos turísticos. Consideramos con ello que es una línea de investigación que se mantiene abierta para futuros trabajos. Esperamos, así mismo, que esta demanda sea considerada por las administraciones y organismos competentes.

\section{BIBLIOGRAFÍA}

AA. VV. (2007): «La oferta de un producto turístico diferenciado y de calidad; posible pilar para el desarrollo rural. Las rutas alimentarias como modalidad de Turismo Rural». IX Reunión de Economía Mundial Madrid, abril de 2007. www.uam.es/otros/ixrem/Comunicaciones/

AA. VV. (2008): En CARREÑo, F. y RIQUelme, P. J. (Editores) Acerca del desarrollo rural. Perspectivas sobre el medio rural desde la Región de Murcia. Murcia, Servicio de Publicaciones de la Universidad de Murcia. 57-76. 
ANDRÉS, J. L. y MiLlÁN, M. (2001): «Diagnóstico socioeconómico para la rehabilitación de las ciudades del Noroeste Murciano». Estudios Históricos y Geográficos para la recuperación de los cascos históricos del Noroeste de la Región de Murcia. Universidad de Murcia, 7-94.

ANTÓN, S. (2004): «De los procesos de diversificación y cualificación a los productos turísticos emergentes. Cambios y oportunidades en la dinámica reciente del turismo litoral». Papeles de economía española, $\mathrm{n}^{\circ}$ 102, 316-333.

Blanquer, D. (dir.) (2006): Turismo en espacios rurales. $8^{\circ}$ Congreso de Turismo, Universidad y Empresa. Valencia, Edición de Tirant Lo Blanch.

Bote, V. (1988): Turismo en espacio rural, rehabilitación del patrimonio sociocultural y de la economía local. Madrid, Edit. Popular.

CANOvÉS, G.; HerRerA, L.; BlAnCO, A (2005.: «Turismo rural en España: Un análisis de la evolución en el contexto europeo». Cuadernos de Geografía no 77, 4158.

CEBrián, F.; GARCÍA, J. A. (2010): «Propuesta metodológica para la identificación, clasificación y puesta en valor de los recursos territoriales del turismo interior. La provincia de Albacete». Boletín de la A. G. E. n 54: 361-383.

Comisión EuropeA, (1990): Comunicación «Medidas Comunitarias para el Fomento del Turismo Rural» COM 90/438.

Comisión de las Comunidades EuRopeas (1994b): Marco Comunitario de Apoyo para el desarrollo y ajuste estructural de las regiones menos desarrolladas. España. Objetivo no 1, 1994-1999. COM (94) 1666, Bruselas.

Comisión Europea/DG VI (1997): Rural Developments, CAP 2000, Documentos de trabajo.

Comunidad AutónOma de la Región De MurCia: Programa de Desarrollo Rural FEADER de la Región de Murcia 2007-2013. Murcia, 2007.

CONSEJERÍA DE CULTURA Y TURISMO REGIÓN DE MuRCIA: Las cifras del Turismo en la Región de Murcia 2010. Secretaría General Unidad de Estudios y Estadística Región de Murcia, 2011.

Consejería de Cultura y Turismo Región de Murcia: Turismo en la Región de Murcia 2010. Secretaría General Unidad de Estudios y Estadística Región de Murcia, 2011.

Decreto $N^{\circ} 79 / 1992$, de 10 de septiembre, por el que se regula la actividad de alojamientos turísticos especiales en zonas de interior. Boletín Oficial de la Región de Murcia, 24 septiembre de 1992, no 223 p. 6915.

Decreto $N^{o} 76 / 2005$, de 24 de junio, por el que se regulan los alojamientos rurales. Boletín Oficial de la Región de Murcia, 11 de julio de 2005, nº 157 p. 16651.

FUENTES, R. (2008). «El turismo rural en España en 2007». La Actividad Turística Española en 2007. AECIT. Madrid, Editorial Centro de Estudios Ramón Areces.

GARCÍA, J. L. (1996): «El Turismo Rural como factor diversificador de rentas en la tradicional economía agraria». Estudios Turísticos n ${ }^{\circ} 132,47-61$

InFORME InTERmedio AnUAL. Año 2009 Programa de Desarrollo Rural de la Región de Murcia 2007-2013 Consejería de Agricultura y Agua de la Región de Murcia.

Ley 11/1997, de 12 de diciembre, de Turismo de la Región de Murcia. Boletín Oficial de la Región de Murcia 
Ley 45/2007, de 13 de diciembre, para el desarrollo sostenible del medio rural. Boletín Oficial Del Estado no 299 de 14 de diciembre de 2007.

LÓPEZ, D., (1998): La ordenación y planificación integrada de los recursos territoriales turísticos. Castellón de la Plana, Publicaciones Universitat Jaume I.

MartíneZ, S. (2005): «Museo del Vino de Bullas: Génesis y perspectivas», Actas I Congreso sobre Etnoarqueología del vino (Bullas, 4-6 noviembre 2004), Murcia: Universidad de Murcia, 11-21.

MaYA, A.; SÁnchez, M. J.; CoRTizo, J.; HidAlgo, C. (2008): «Implicaciones territoriales y socioeconónmicas del Fondo Europeo Agrícola de Desarrollo Rural (FEADER) en la provincia de León». En ARAQUE et AL. (2008): Las agriculturas españolas y la Política Agraria Comunitaria: 20 años después. XIII Coloquio de Geografía Rural, 873-888.

Millán, M. (1998): «Análisis de la dinámica de un municipio impactado por el turismo rural. El ejemplo de Moratalla». Cuadernos de Turismo. $\mathrm{n}^{\circ}$ 1, 99-115.

Millán, M. (2000): «Notas para la catalogación como municipios turísticos en el interior de la Región de Murcia». Cuadernos de Turismo n 5, 87-104.

Millán, M. (2004): «Turismo en la Región de Murcia: Evolución de la oferta turística de interior y su distribución espacial». Cuadernos de Turismo $\mathrm{n}^{\circ}$ 13, 51-72.

Millán, M. (2004): La Iniciativa Comunitaria LEADER en el desarrollo local del Noroeste murciano, Murcia, Servicio de Publicaciones de la Universidad de Murcia.

Millán, M. (2007): «Procedimientos para el desarrollo rural en la Región de Murcia. Horizonte 2006», Investigaciones Geográficas nº 42, 145-159.

Millán, M. (2007): «La competitividad territorial como fundamento del desarrollo sostenible en destinos turísticos de interior: el caso de Caravaca de la Cruz». En: Las Administraciones públicas y empresas turísticas ante el reto de la sostenibilidad, XI Congreso AECIT. Murcia, Universidad Católica San Antonio, AECIT, 303-324.

Millán, M. (2008): «Herramientas para el posicionamiento competitivo de los espacios rurales. Región de Murcia». En CARREÑo, F. y RiQUELME, P. J. (eds.) Acerca del desarrollo rural. Perspectivas sobre el medio rural desde la Región de Murcia. Murcia, Servicio de Publicaciones de la Universidad de Murcia, 5776.

MiLlÁN, M. (2009): «Enoturismo. Herencia e Innovación como herramientas para el desarrollo rural de Bullas». En LÓPEZ OLIVARES et AL.: Innovación, creatividad y nuevos modelos de gestión en turismo. Valencia, Tirant lo Blanch, 91-126.

Oficina de Publicaciones Oficiales de las CoMunidades EuRopeas: El enfoque LEADER: Guía básica. Luxemburgo, 2006.

Ministerio de Agricultura, Pesca y Alimentación. Plan Estratégico Nacional de Desarrollo Rural 2007-2013 (Borrador). Madrid, 29 de junio de 2006. Decisión del Consejo de 20 de febrero de 2006.

PEÑAlVER, M. T. y MiLlán, M. (2006): «Emergencia de un espacio turístico: el Valle de Ricote en la Región de Murcia». En LACOSTA, A. J. (coord.) (2006): IX Coloquio de Geografía del Turismo Ocio y Recreación. Turismo y cambio territorial: ¿eclosión, aceleración, desbordamiento? Zaragoza, Prensas Universitarias de Zaragoza, 193-204. 
PlaZA, J. I. (2005): «Desarrollo y diversificación en las zonas rurales de España: el Programa PRODER». Boletín de la A.G.E. n 39, 399-422

PicAzo, H., FAlCó, L., SÁncheZ, E (2009): «El turismo rural en la Región de Murcia. Análisis de tendencias». Colección Estudios n²7 capítulo III. Murcia, Consejo Económico y Social de la Región de Murcia (CES).

PULIDO FERNÁNDEZ, J. I. (Coord.) (2008): El turismo rural. Estructura económica y configuración territorial en España. Madrid, Editorial Síntesis, 345.

RYAN, C. (1995): Researching tourist satisfaction: Issues, concepts, problems. Londres, Routledge.

RYAN, C. (1997): The tourist experience: A new introduction. Londres, Cassell.

VALDÉS, L. (2004): «El turismo rural: una alternativa diversificadora. Líneas estratégicas de su expansión». Papeles de Economía Española, nº102, 298-315. 